ARTICLE

https://doi.org/10.1038/s41467-018-08238-y

\title{
Earthquake lubrication and healing explained by amorphous nanosilica
}

\author{
Christie D. Rowe (D) ${ }^{1}$, Kelsey Lamothe ${ }^{1}$, Marieke Rempe ${ }^{2,7}$, Mark Andrews ${ }^{3}$, Thomas M. Mitchell ${ }^{4}$, \\ Giulio Di Toro (1) ${ }^{2,5}$, Joseph Clancy White ${ }^{6} \&$ Stefano Aretusini ${ }^{5}$
}

During earthquake propagation, geologic faults lose their strength, then strengthen as slip slows and stops. Many slip-weakening mechanisms are active in the upper-mid crust, but healing is not always well-explained. Here we show that the distinct structure and ratedependent properties of amorphous nanopowder (not silica gel) formed by grinding of quartz can cause extreme strength loss at high slip rates. We propose a weakening and related strengthening mechanism that may act throughout the quartz-bearing continental crust. The action of two slip rate-dependent mechanisms offers a plausible explanation for the observed weakening: thermally-enhanced plasticity, and particulate flow aided by hydrodynamic lubrication. Rapid cooling of the particles causes rapid strengthening, and inter-particle bonds form at longer timescales. The timescales of these two processes correspond to the timescales of post-seismic healing observed in earthquakes. In natural faults, this nanopowder crystallizes to quartz over 10s-100s years, leaving veins which may be indistinguishable from common quartz veins.

\footnotetext{
${ }^{1}$ Earth and Planetary Sciences, McGill University, Montréal, QC H3A OE8, Canada. ${ }^{2}$ Dipartimento di Geoscienze, Università degli Studi di Padova, Via Gradenigo 6, 35131 Padova, Italy. ${ }^{3}$ Department of Chemistry, McGill University, 801 Sherbrooke St. W., Montréal, QC H3A OB8, Canada. ${ }^{4}$ Rock and Ice Physics and UCL Seismological Laboratory, Earth Sciences Department, University College London, Gower Street, London WC1E 6BT, UK. ${ }^{5}$ Sezione di Tettonofisica e Sismologia, Istituto Nazionale di Geofisica e Vulcanologia, Roma, Italy. ${ }^{6}$ Department of Earth Sciences, University of New Brunswick, Fredericton, NB E3B 5A3, Canada. ${ }^{7}$ Present address: Institute for Geology, Mineralogy, and Geophysics, Ruhr-Universität Bochum, Universitätsstr. 150, 44780 Bochum, Germany. Correspondence and requests for materials should be addressed to C.D.R. (email: christie.rowe@mcgill.ca)
} 
S lip weakening is fundamental to all earthquakes ${ }^{1}$, but there is no known universal mechanism for controlling the loss of rock strength ${ }^{2,3}$. The lack of positive heat flow anomalies around major continental faults suggests that the shear resistance on faults may be extremely low during displacement, but paradoxically, stresses near the faults may be high ${ }^{4}$. The proposal of "silica gel" lubrication, thought to cause extreme loss of shear resistance in high velocity friction experiments on quartz-rich rock, offered a tantalizing explanation for dramatic coseismic weakening which might apply broadly within continental crust ${ }^{5,6}$. The weakening effect is apparently associated with the availability of water, and is potentially inhibited when experiments are performed under dry conditions, although the specific dependency may be complicated $^{7,8}$. In experiments, the strength of sheared interfaces recovers over minutes to hours after shearing $5,6,9,10$, but the causes and mechanisms remain enigmatic. We performed shearing experiments on quartz-rich rock, but did not find evidence for silica gel, where gel is a "jellylike substance formed by a colloidal solution in its solid phase"11. Here we show the composition and structure of the frictional wear material and propose an alternative explanation for the lubricating and healing behaviors.

\section{Results}

Friction experiments. Novaculite (chert) cores were acquired from Dan's Whetstone Company, Percy, Arkansas, USA. The novaculite occurs in the whetstone quarry as cherty nodules within low-grade limestone. The novaculite consists of a porous aggregate of euhedral $\sim 10 \mu \mathrm{m}$ quartz grains with traces of calcite and oxide minerals, and abundant fluid inclusions along grain boundaries and healed fractures. The friction experiments were conducted at the Department of Geosciences of the Universit'a degli Studi di Padova, Padua, Italy, using the ROtary-Shear Apparatus ROSA. Two cylinders were sheared against each other at atmospheric humidity. After the experiment, the sample halves were recovered from the machine as one in order to preserve the wear material.

Shearing experiments were performed at equivalent velocities (as defined by ${ }^{12}$ ) of $100 \mu \mathrm{m} / \mathrm{s}, 1 \mathrm{~mm} / \mathrm{s}, 1 \mathrm{~cm} / \mathrm{s}$, and $10 \mathrm{~cm} / \mathrm{s}$ at normal stresses of $2.5 \mathrm{MPa}$ for total displacements of $3 \mathrm{~m}$ and $30 \mathrm{~m}$ (Table 1). Weakening was observed in every experiment, and most experiments achieved a steady state friction value after $>0.3 \mathrm{~m}$ of slip. The friction coefficient evolved from $\sim 0.7$ gradually to a steady state value of $\sim 0.45-0.6$ in the $100 \mu \mathrm{m} / \mathrm{s}$, $1 \mathrm{~mm} / \mathrm{s}$, and $1 \mathrm{~cm} / \mathrm{s}$ experiments, and decreased dramatically to < 0.1 in the $10 \mathrm{~cm} / \mathrm{s}$ experiments (Fig. 1a).

\begin{tabular}{|c|c|c|c|c|c|c|}
\hline Sample run & Equivalent velocity $(\mathrm{m} / \mathrm{s})$ & $\begin{array}{l}\text { Total slip } \\
\text { (m) }\end{array}$ & $\begin{array}{l}\text { Normal stress } \\
(\mathrm{MPa})\end{array}$ & $\begin{array}{l}\text { Bulk } \Delta T\left({ }^{\circ} \mathrm{C}\right) \text { from } \\
\text { FEM model }\end{array}$ & $\begin{array}{l}\text { Bulk } \Delta T\left({ }^{\circ} \mathrm{C}\right) \text { from half-space } \\
\text { analytical solution }\end{array}$ & $\begin{array}{l}\text { Peak } \Delta T_{\text {flash }} \\
\left({ }^{\circ} \mathrm{C}\right)\end{array}$ \\
\hline $95^{\star}$ & $0.1 \mathrm{~m} / \mathrm{s}$ in $2 \mathrm{~s}$ (velocity ramp) & 1 & 2.5 & - & - & - \\
\hline 96 & 0.1 & 3 & 2.5 & 28.5 & 42.5 & 1006 \\
\hline $97^{\star}$ & 0.1 & 3 & 2.5 & 23.6 & 45 & 1006 \\
\hline 100 & 0.1 & 3 & 2.5 & - & - & 1006 \\
\hline $101^{\star}$ & 0.1 & 3 & 2.5 & - & - & 1006 \\
\hline $102^{\star}$ & 0.1 & 30 & 2.5 & - & - & 1006 \\
\hline 110 (failed) & 0.001 & 3 & 2.5 & - & - & - \\
\hline $111^{\star}$ & 0.01 & 3 & 2.5 & 38.0 & 60 & 318.2 \\
\hline $112^{\star}$ & 0.0001 & 3 & 2.5 & 2.8 & 7 & 31.8 \\
\hline
\end{tabular}

*denotes runs whose wear material was characterized in detail with one or more of TEM, SEM, FT-IR, and Raman Spectroscopy
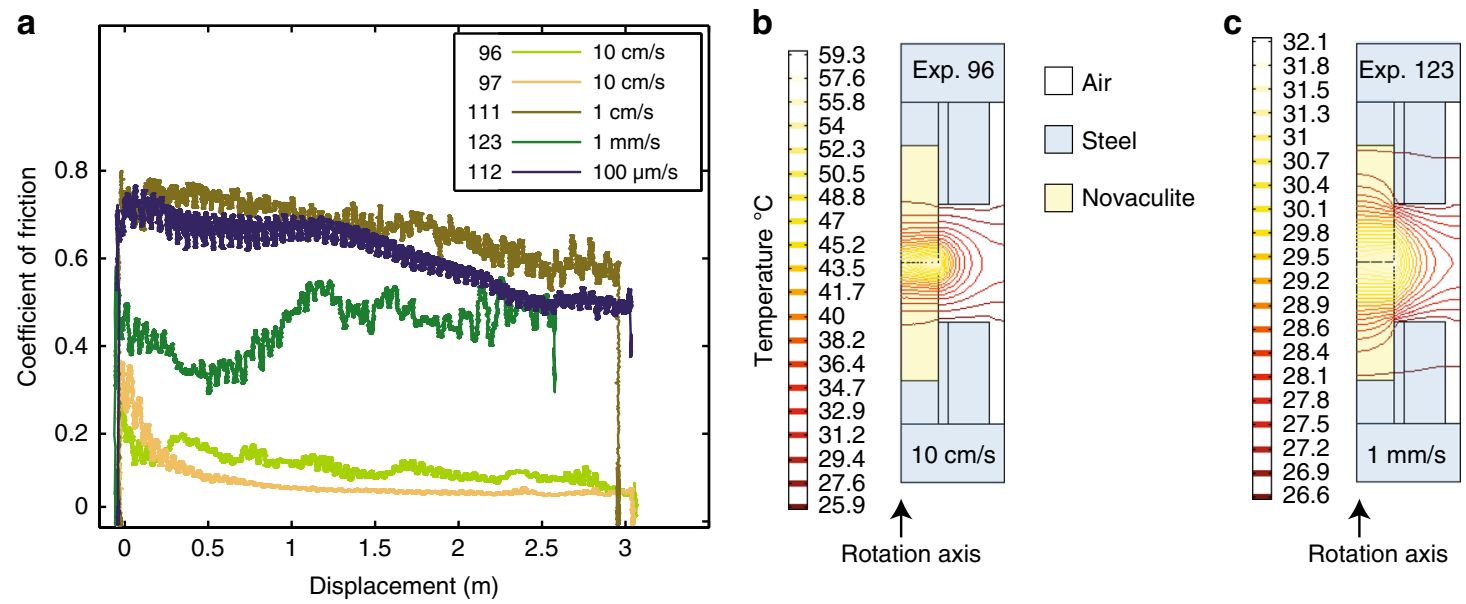

Fig. 1 Results of friction and numerical experiments. a Coefficient of friction vs. displacement in novaculite friction experiments. b Temperature distribution from finite element model at the end of the experiments for fastest slip rate $(10 \mathrm{~cm} / \mathrm{s}$, experiment 96$)$ and $\mathbf{c}$ slower experiment (1 mm/s, experiment 123$)$ 
We estimated the bulk temperature rise of the slipping zone during the experiments using two methods: a finite element model with Comsol Multiphysics and a half-space analytical solution ${ }^{13}$. Fig. 1b, $c$ show the geometry of the half-model, with novaculite in the center (density $=2750 \mathrm{kgm}^{-3}$, thermal diffusivity $=5 \mathrm{~m}^{2} \mathrm{~s}^{-1}$,

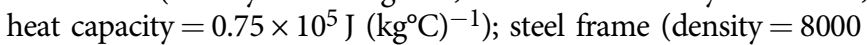
$\mathrm{kgm}^{-3}$, thermal diffusivity $=16 \mathrm{~m}^{2} \mathrm{~s}^{-1}$, heat capacity $=0.5 \times 10^{5} \mathrm{~J}$ $\left.\left(\mathrm{kg}^{\circ} \mathrm{C}\right)^{-1}\right)$, in contact with air (density $=0 \mathrm{~kg} / \mathrm{m}^{3}$, thermal diffusivity $\left.=1 \mathrm{~m}^{2} \mathrm{~s}^{-1}, \mathrm{~J}\left(\mathrm{~kg}^{\circ} \mathrm{C}\right)^{-1}\right)$. The Comsol model incorporated timevarying friction measured during the experiment as an input. Both approaches show average slipping zone temperature rises of $\leq 60^{\circ}$ in every experiment (Table 1 ). We also estimated the peak temperature at asperities during flash heating using the approach of Violay et al. ${ }^{14}$ for a range of slip rates and asperity sizes. The results of temperature calculations are presented in Figs. 1, 2 and Table 1.

Microstructure and composition of wear material. The starting material (novaculite) is composed mostly of $\sim 10-50 \mu \mathrm{m}$ quartz with trace amounts of calcite and has rough-walled pores about $100 \mu \mathrm{m}$ in diameter (Fig. 3a). In all experiments, wear material on the sheared interface formed a $\sim 5-30 \mu \mathrm{m}$-thick layer of $<1 \mu \mathrm{m}$ ellipsoidal particles (Fig. 3b, c, Fig. 4). High sphericity is characteristic of amorphous silica nanoparticles ${ }^{15}$, so rolling is not required to explain their shape. The particles form clusters up to 100-1000 nm across (Fig. 3) which explode under the electron beam, suggesting the presence of volatiles (Fig. 3c; compare to ${ }^{16}$ ). The nanopowder layer is cut by discrete slip surfaces $\sim 1 \mu \mathrm{m}$ thick (Fig. 3b, white arrows). When the novaculite cores are opened to expose the sliding surface in plan view (Fig. 3c-f), the thin localized shears are revealed to be formed of discrete dense plates with smooth surfaces marked by slip-parallel striations, interlayered within the nanopowder layer (Fig. 3e-f). We interpret these plates as the remnants of discrete slip surfaces. Fragments of plates are found in the inter-plate nanopowder (Fig. 3f), showing

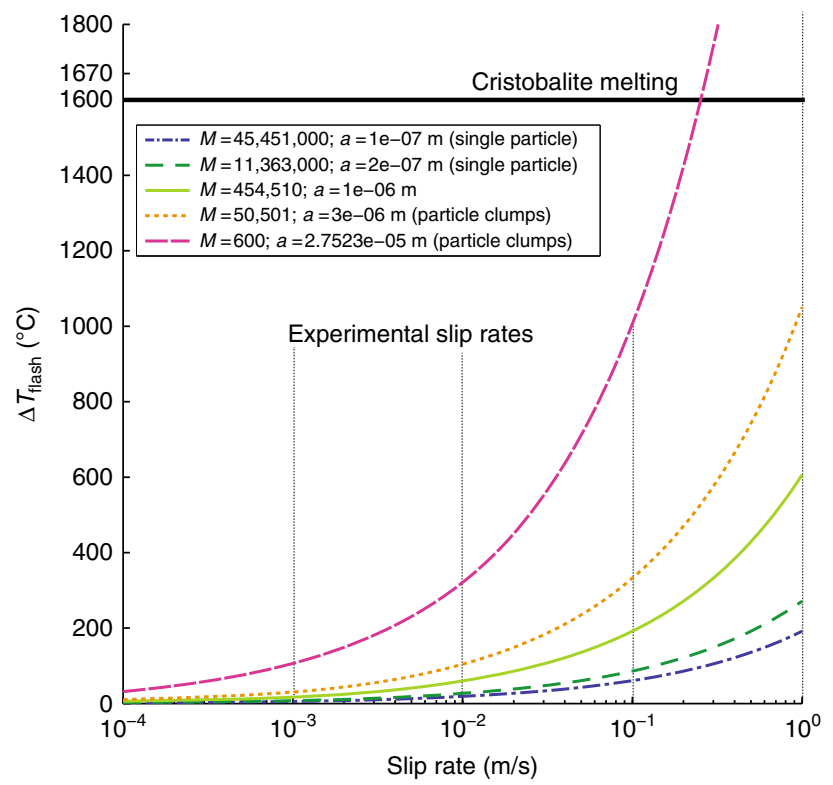

Fig. 2 Flash heating temperature at asperities. Temperatures calculated for slip rates from $10^{-4}-10^{0} \mathrm{~m} / \mathrm{s}$ at normal stress $=2.5 \mathrm{MPa}$, showing the effect of asperity size $(a)$ and number $(M)$, between the size of single particles $(10 \mathrm{~nm})$ to the size of particle clumps $(100 \mathrm{~s} \mu \mathrm{m})$. The maximum flash heating temperature for any of our experiments is estimated to be $\sim 1000^{\circ} \mathrm{C}$. Melting temperature of cristobalite is plotted for reference that development, breaking and reforming of striated plates occurred during a single experiment. The sliding surface of the novaculite underneath the wear material displays a shiny polish (Fig. 3d, ss). This polish is due to smoothing of the novaculite surface by initial abrasion, as well as by smearing and adhesion of nanopowder across the novaculite to fill surface pores. We observe no evidence of viscous fluids on the slip surfaces, so no evidence supports the formation of gel or melt during the experiments (consistent with ${ }^{9}$, c.f ${ }^{3}$ ).

We used transmission electron microscopy (TEM) to examine the crystallinity and nanostructure of the wear material (Fig. 4). The nanopowder is predominantly composed of $100-1000 \mathrm{~nm}$ clumps of rounded to ellipsoidal amorphous nanoparticles, $\sim 10-100 \mathrm{~nm}$ in diameter, and chips of quartz (Fig. 4, similar to $\left.^{9}\right)$. The relict quartz grains are larger $(\leq 1 \mu \mathrm{m}$; Fig. $4 \mathrm{a}, \mathrm{b}$, white arrows), and have stepped, fractured edges showing damage caused by comminution and frictional wear. The powder layer contains angular fragments of more densely packed particles (Fig. 4c) which correspond to the shiny striated plates (Fig. 3e-f). At the sub-micron scale, it is clear that the sharp shiny plate is formed from gradational packing of the same amorphous nanoparticles, with increasing packing density toward the shiny slip surface (along white arrows in Fig. 4c). The fragments of broken slip surfaces are rotated relative to one another (as demonstrated by opposite directions of gradational packing in the two fragments of Fig. 4c), confirming that the slip surfaces formed and were broken up into fragments during sliding.

Raman spectroscopy was employed to characterize $\mathrm{Si}-\mathrm{O}$ bonding in the nanopowder for comparison to crystalline and amorphous species of silica, and investigate the form of any water present. We used a $633 \mathrm{~nm} \mathrm{He-Ne} \mathrm{excitation} \mathrm{laser} \mathrm{Raman}$ microprobe spectrometer in the Materials Chemistry lab at McGill University. Spectra were collected from the powdered novaculite (starting material), the wear material, and a control nanosilica (a lab-made $2 \mu \mathrm{m}$ nanosilica powder, Nyacol Nyasil 5; Fig. 5a). Shear-related structures were also interrogated without physical disturbance by using Confocal Raman microspectroscopy in situ (Fig. 6). Spectra were collected at evenly spaced points along transects from core to rim across the samples (Fig. 6).

The novaculite is an exact match for $\alpha$-quartz ${ }^{17}$. The wear material spectra show a broad peak with weak structure in the region $100-600 \mathrm{~cm}^{-1}$ punctuated by sharp peaks due to minor contributions from $\mathrm{E}$ (phonon) and A1 modes in $\alpha$-quartz from the exposed patches of novaculite beneath the wear layer (Fig. $3 \mathrm{c}$, ss; Fig. 5a; Fig. 6). Compared with typical signatures of amorphous silica, the classic modes associated with oligomeric ring structures are absent in our wear material (red bands in Fig. 5a), indicating that a variety of $\mathrm{Si}-\mathrm{O}$ species are present with no dominant modes (see Supplementary Discussion for additional description). The strong polarization-dependence across all wavelengths (Fig. 5a) indicates that the wear material displays anisotropy, perhaps related to the shear-parallel smearing observed in the striated plates and on the slip surface (Fig. 3d-e). No silanol $(\mathrm{Si}-\mathrm{OH})$ or adsorbed water were observed by Raman (scans out to $4000 \mathrm{~cm}^{-1}$, not shown in Fig. 5a; ${ }^{18}$ ). This spectrum is unlike previously published Raman spectra of glassy silica ${ }^{15}$ or commercial nanosilica we analyzed (see Supplementary Discussion for details). In summary, the nanosilica wear material formed by shearing of quartz-rich rocks is amorphous but anisotropic, is anhydrous within the detection limit of Raman spectroscopy, and has a unique Raman fingerprint, distinguishable from amorphous silica from other sources.

The quantity of wear material on the slip surface varied with slip rate (Fig. 6), for experiments with the same amount of slip (Table 1). Some wear material was ejected and lost during the 

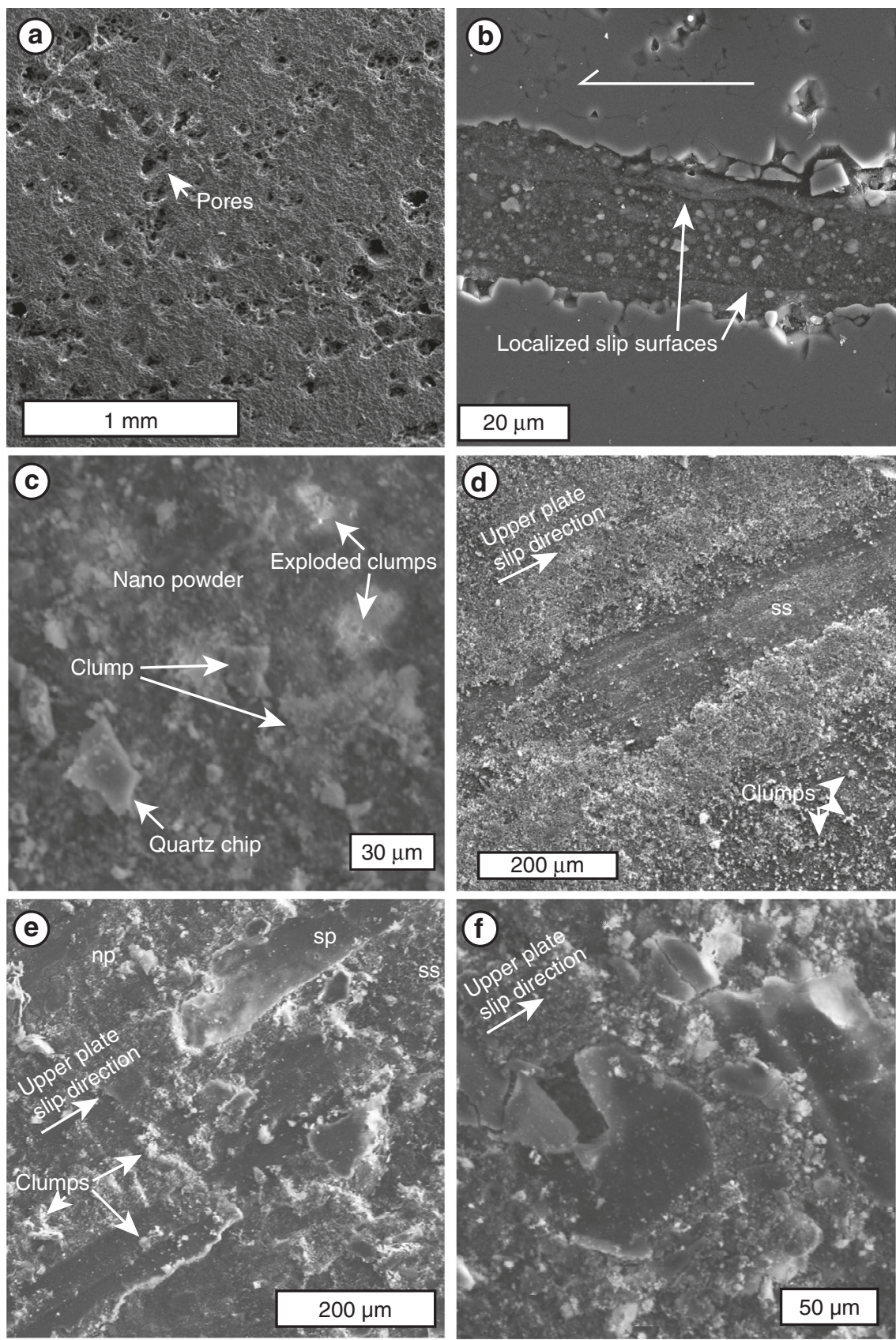

Fig. 3 Secondary electron images of microstructures in novaculite and wear material, collected with JEOL 8900 microprobe at McGill University (beam current $=20 \mathrm{kV}$ ). Images $\mathbf{a}$ and $\mathbf{c}-\mathbf{f}$ are of experiment 97 . Image $\mathbf{b}$ is of experiment 101 . a Surface of unsheared novaculate (starting material) with empty $(100 \mu \mathrm{m})$ pores. $\mathbf{b}$ Cross-sectional view of wear material layer. White arrows indicate thin slip zones composed of compressed powder. $\mathbf{c}$ View normal to slip surface (ss) that was opened by separating novaculite cores. Clumps of ellipsoidal powder grains decorate surface and adhere to striated slip surface. Uneven distribution of wear material leaves exposed patches of slip surface with remaining $10 \mu \mathrm{m}$ pores. d Nanopowder (np) compressed into striated plates (sp) parallel to slip direction. e Broken fragments of striated plates, interlayered with nanopowder, displaying development and cataclasis of multiple slip surfaces during single shear experiment. $\mathbf{f}$ Closeup on wear powder showing quartz chips, $10 \mu \mathrm{m}$ clumps, and $1 \mu \mathrm{m}$ particles. Bright clusters show debris from clumps which exploded during observation

experiments and during sample unloading, so our observation is only qualitative. However, comparing Experiments $111(1 \mathrm{~cm} / \mathrm{s})$ and $112(100 \mu \mathrm{m} / \mathrm{s})$ shows that more of the surface is covered with wear material and the layer is thicker in the faster experiment (Fig. 6). On sample 111, which displayed extreme weakening (Fig. 1), in situ Raman transects across the sliding surface shows quartz peaks across the center $\sim 30 \%$ of the diameter, while amorphous wear material covers the outer $\sim 70 \%$, and the wear material is collected into dense smooth packs or plates which are concentrically smeared in the slip direction (Figs. $3,6)$. On sample 112, which did not display substantial weakening (Fig. 1a), quartz peaks appear in the Raman transect in the center $\sim 50 \%$ of the diameter, and in the outer rim of wear material, the powder is more evenly distributed. This observation of increased wear and amorphization at higher slip speeds is similar to previous experiments on clay-quartz mixtures ${ }^{19}$. 

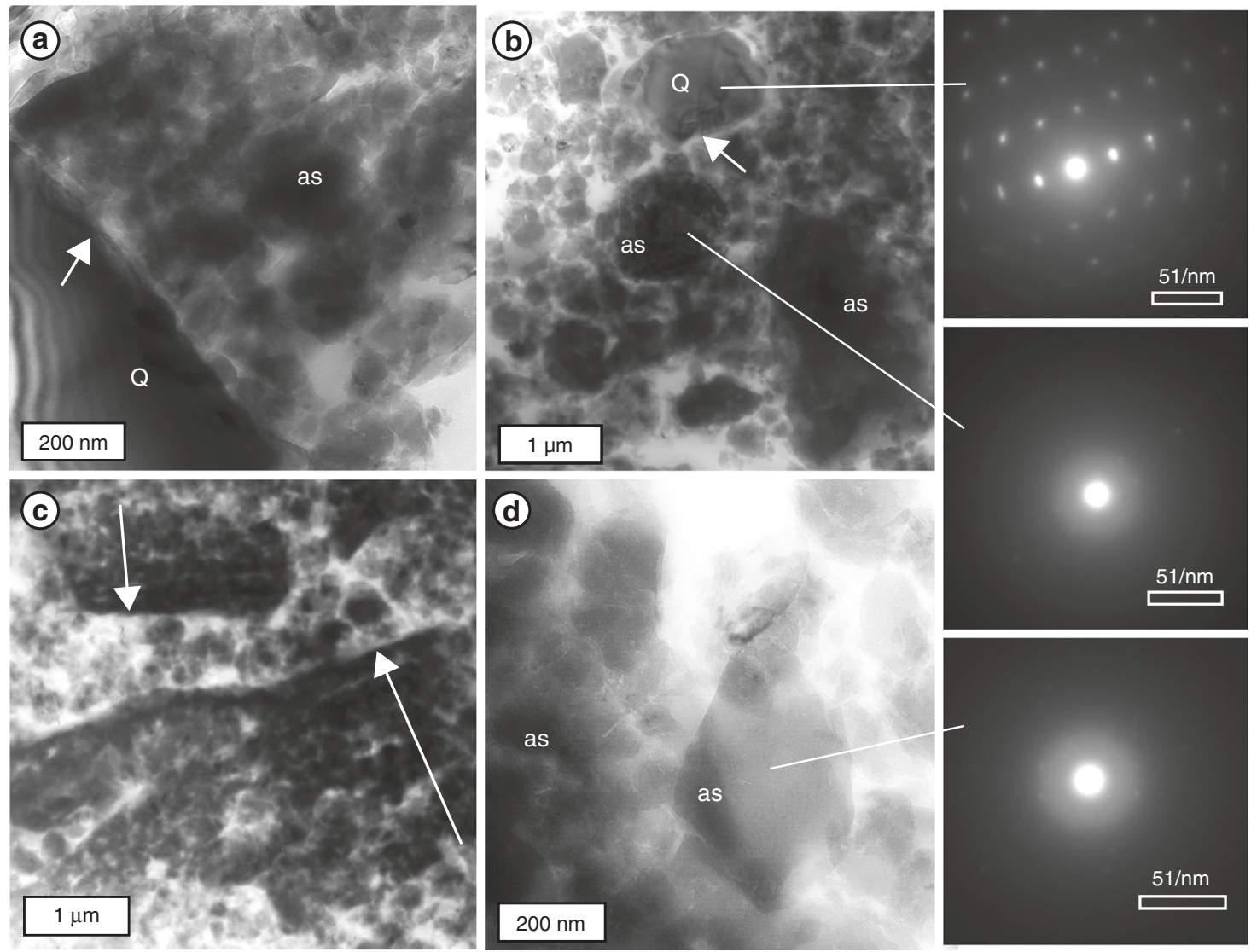

Fig. 4 Transmission Electron Microscope images of wear material from experiment 101 (brightfield). a Quartz grain (Q) with rough fractured surface (white arrow). Clumps of amorphous silica particles (as) surround quartz grain. $\mathbf{b}$ Chips of crystalline quartz (top selected area electron diffraction pattern) and rounded clumps of amorphous particles (middle selected area electron diffraction pattern). At the scale of this image, nearly all amorphous silica grains are composites of smaller particles and fragments. c Broken fragments of striated plates composed of amorphous nanoparticles. Sharp slip surface composed of gradationally increasing packing density of particles toward slip surface (white arrows). Fragments are floating in loosely packed amorphous nanopowder. $\mathbf{d}$ Wear powder of rounded to elongate particles with grain size 10-100 nm that show no crystal structure (bottom selected area electron diffraction pattern)

In order to look for the presence of silanol $(-\mathrm{Si}-\mathrm{O}-\mathrm{H})$, Fourier Transform Infrared (FT-IR) spectroscopy was collected using a PerkinElmer Spectrum TWO FT-IR instrument with a singlebounce diamond ATR crystal. The wear material displays FT-IR absorption band patterns distinct from both powdered novaculite (which matches $\alpha$-quartz ${ }^{20}$ ) and commercial amorphous nanosilica (Fig. 5b; Supplementary Note 1). The wear material spectra display features absent in the powdered novaculite, indicative of adsorbed $\mathrm{H}_{2} \mathrm{O}$ and silanol bending (Fig. 5b, Table 2), consistent with Hayashi et al. ${ }^{9}$, and the absorbances for stressed $\mathrm{Si}-\mathrm{O}-\mathrm{Si}$ bonds are more pronounced than in the powdered novaculite. We observe water and silanol in the FT-IR spectra, but no evidence of silanol or hydroxyl was detected in the Raman spectra. As the detection limits of the FT-IR are $\sim 10,000 \times$ lower than the Raman for hydroxyl and silanol, this result is consistent with a nanoparticle structure characterized by a thin hydrated silica layer rim surrounding an anhydrous amorphous silica core.

\section{Discussion}

We have shown that the lubricating wear material produced in moderate to fast slip rate experiments on novaculite consists of spherical nanoparticles of amorphous silica with hydrated surfaces. Quartz can be amorphosed by high isotropic pressures $(\sim 15-25 \mathrm{GPa})$, comminution in a mortar and pestle at room conditions, or shock pressurization ${ }^{21,22}$. At similar normal load to our experiments ( $5 \mathrm{MPa})$, prepared quartz surfaces showed fractal distribution of contact size with an average contact stress on the order of $5 \mathrm{GPa}^{23}$, similar to the estimated contact stresses which generated amorphous wear material in previous experiments ${ }^{10}$. It follows that the smaller contacts would experience stresses above the isotropic amorphization stress $(\sim 15-25 \mathrm{GPa})$ even under static loading conditions. Experiments on nanocrystalline silicon showed that pressure induced amorphization (at $19 \mathrm{GPa}$ ) produced meta-stable supercooled glass which persisted after depressurization ${ }^{24}$, potentially analogous to production of our amorphous particles. It is not clear whether comminution causes amorphization due to creating highly variable stress conditions resulting in locally reaching the isotropic amorphization stress, or whether an additional mechanical or thermal effect lowers the amorphization threshold ${ }^{22,25}$. In the case of comminution, high sphericity of wear particles appears to be a result of strain minimization in the material ${ }^{25}$. Amorphous silicate has been produced in other experiments at lower slip rates ${ }^{26}$ and at lower slip rates with higher temperatures ${ }^{27}$, without significant weakening, so it may be necessary for sufficient slip to form a continuous amorphous layer for weakening to occur ${ }^{5}$.

Comparison of the wear material from experiments at different slip rates showed that the nanopowder was indistinguishable in 
a

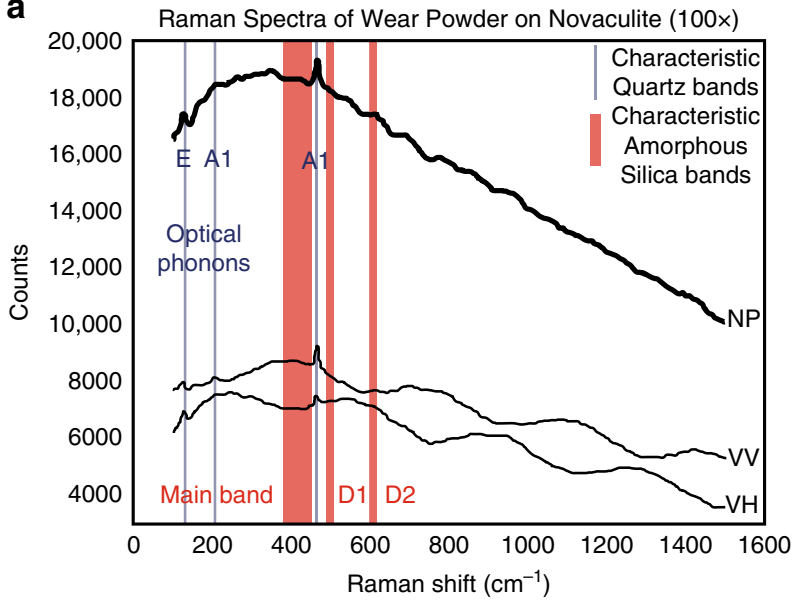

b

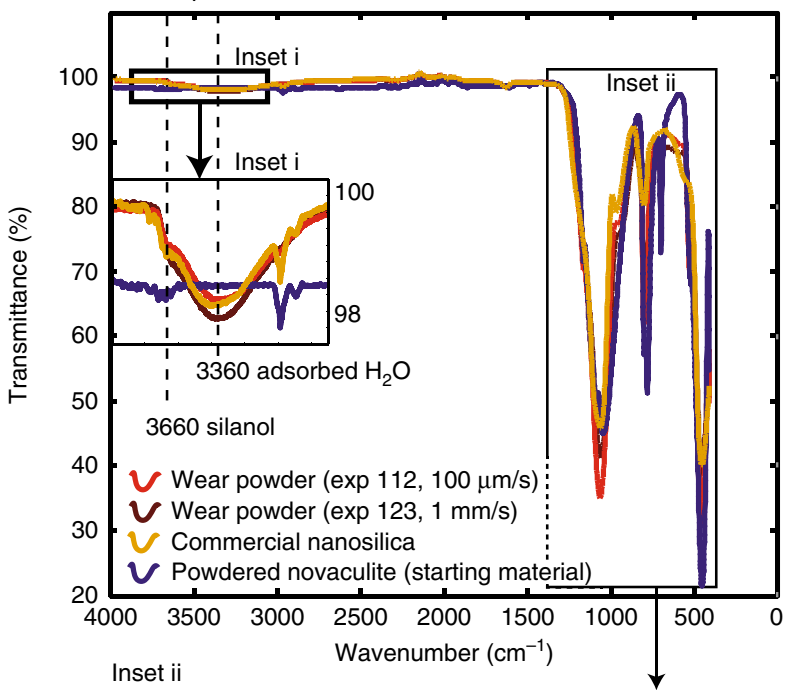

Fig. 5 Raman and FT-IR spectra. a Raman spectra of the sliding surface showing non-polarized (NP) and decomposed polarized spectra (VH, VV; where first letter $(\mathrm{V})$ refers to the vertical polarization direction of the laser, and second letter $(\mathrm{H}=$ horizontal, $\mathrm{V}=$ vertical $)$ to the orientation of the analyzer). Red bars are normal vibration modes for commercial amorphous silica ${ }^{31}$. b FT-IR spectra of powdered novaculite (starting material), frictional wear powder from two shearing experiments and commercial nano silica. Small absorption peaks at 694 and $1163 \mathrm{~cm}^{-1}$ indicate $\mathrm{Si}-\mathrm{O}$ bond structures are present in the wear material, although not in long-range order (Inset $\mathbf{b}$-ii)

slip rate $(>1 \mathrm{~cm} / \mathrm{s})$ experiments (Fig. 1) must be explained by velocity-dependent properties, not just the presence of the wear material. The post-shearing strengthening $5,6,9$ is dependent on the evolution of material properties during the static hold periods, potentially by time-dependent bonding ${ }^{5,6}$. We explain the rheological observations with two deformation mechanisms that cause weakening and re-strengthening on two different timescales: particulate flow assisted by hydrodynamic lubrication; and intraparticle plasticity (Fig. 7). The action of these two weakening mechanisms together is akin to superplasticity sometimes described in crystalline materials which involves intraparticle deformation, as well as grain-boundary sliding between particles (c.f. ${ }^{28}$ ).

Although the amorphous wear material lacks long-range order, it is still dominated by silica tetrahedra, similar to crystalline species of silica. Si-O bonds which are dangling, stretched, bent (as shown in Fig. 5 and Table 2), or vacancies within and between silica tetrahedra all act as defects within the amorphous silica. Similar to crystalline materials, these defects are concentrated on particle surfaces ${ }^{15}$ ). Variations in the $\mathrm{Si}-\mathrm{O}$ bond angle in silica glasses (including stress-induced variations) cause changes in bulk moduli, solubility in acids, thermal expansion, viscosity, and rates of water diffusion in the glass ${ }^{29}$. Any defect which concentrates stress within the amorphous material plays a role during deformation which is analogous to (and can be modeled as) a dislocation in a crystalline structure, although these 'shear transformation zones' are not geometrically similar to dislocations $\mathrm{s}^{30}$. The exceptional concentrations of defects and vacancies in amorphous silica nanoparticles encourage hydration and plasticity ${ }^{15,20,31}$, especially at the small scales and high pressures as expected at asperity contacts (Fig. $7 \mathrm{a} ;{ }^{32,33}$ ). Yao et al. ${ }^{33}$ have shown that heating, not just the presence of nanoparticles, is important for slip weakening. Hydration effects reduce the glass transition temperature and further promote plastic flow ${ }^{34,35}$. The existence of the smeared nanoparticles forming the striated plates implies that the mild average frictional heating (Fig. 1b) experienced in the shearing experiments at $10 \mathrm{~cm} / \mathrm{s}$ was sufficient to bring local patches above the glass transition temperature, allowing superplastic flow and the cohesion of wear powder to form the striated plates. The shear weakening effect would be reversed upon cooling, within seconds after the cessation of shearing.

Weakening in crystalline nanomaterials has been attributed to the activity of grain boundary sliding ${ }^{36,37}$, but amorphous nanoparticles do not contain crystalline grain boundaries, and could even be work-hardening due to the rapid development of dislocation tangles ${ }^{38}$. Therefore, we invoke a superplastic flow mechanism in our amorphous nanopowders, but the details of the contributing mechanisms may be different than in crystalline wear powders. In amorphous silica, the mechanism of bulk flow is

by silicon-oxygen bond switching and void migration, which can grain size, structure, composition and water content. The lack of discernible difference between the wear material formed in different experiments requires that the differences in shear resistance between the moderate slip rate $(100 \mu \mathrm{m} / \mathrm{s}-1 \mathrm{~cm} / \mathrm{s})$ and fast 

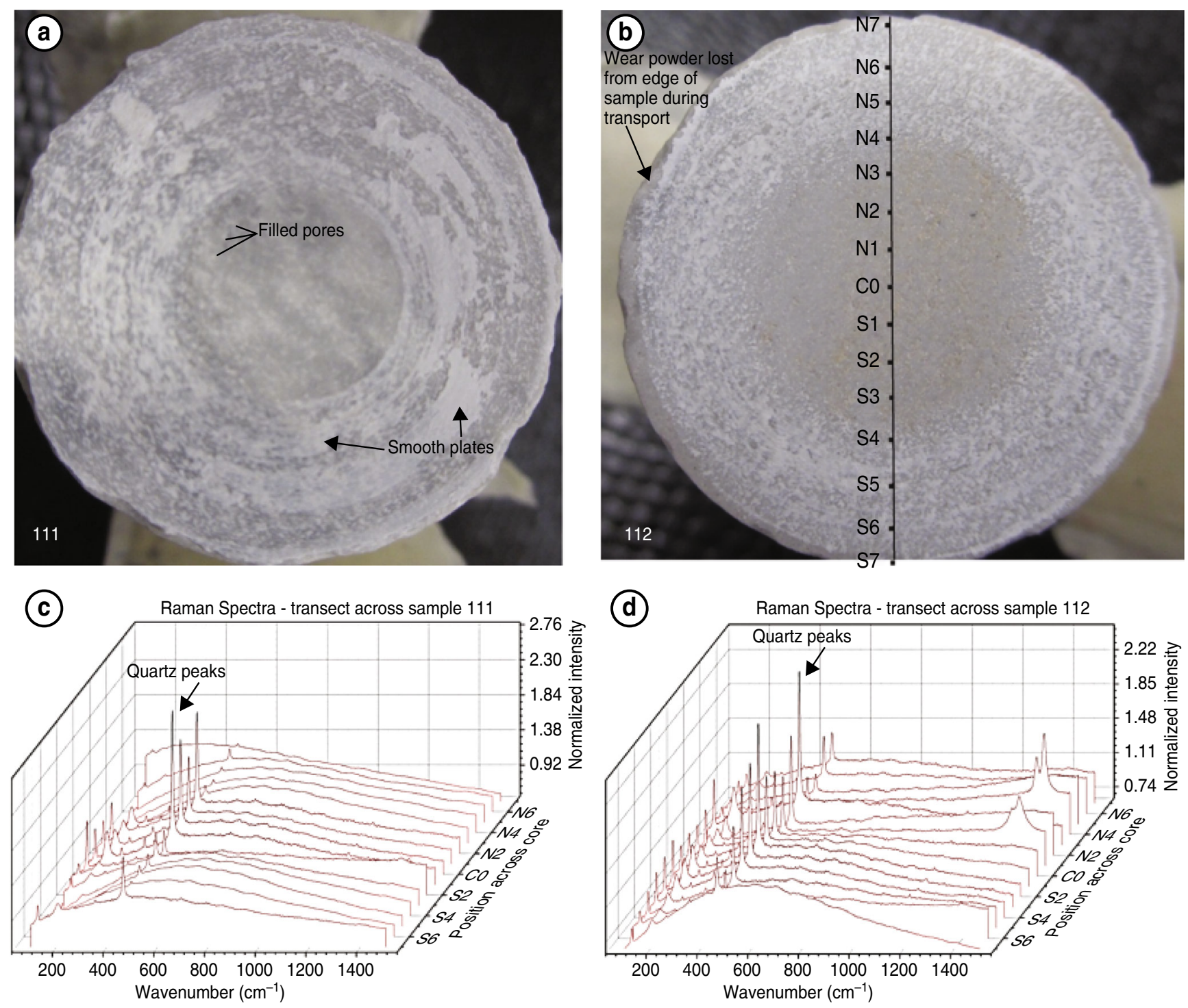

Fig. 6 Photos of shear surfaces and corresponding Raman spectra transects. a Sample 111 ( $1 \mathrm{~cm} / \mathrm{s})$, and b Sample 112 (100 $\mu \mathrm{m} / \mathrm{s})$, showing discontinuous concentric rings of powder on sample surface. Raman spectra from transect scans are shown for each sample (c corresponds to sample 111, $\mathbf{d}$ corresponds to sample 112). The appearance and disappearance of the sharp quartz peaks along the transect can be correlated to the amount of visible wear material in the photos. See text for additional discussion

\section{Table 2 Peak positions in the FT-IR spectra and their corresponding vibrational modes}

Vibrational mode

Position of peak $\left(\mathrm{cm}^{-1}\right)$

\begin{tabular}{|c|c|c|c|c|c|}
\hline & \\
\hline & Nanosilica & $\begin{array}{l}\text { Commercial nanosilica } \\
\text { (this study) }\end{array}$ & $\begin{array}{l}\text { Wear material (this } \\
\text { study) }\end{array}$ & $\begin{array}{l}\text { Powdered novaculite } \\
\text { (this study) }\end{array}$ & $\alpha$-quartz \\
\hline Isolated (free) silanol66 & 3747 & 3745 & & & \\
\hline H-bonded silanol66 & 3660 & 3650 & & & \\
\hline $\begin{array}{l}\text { Asymmetric stretching } \\
\text { of } \mathrm{Si}-\mathrm{O}-\mathrm{Si}^{20}\end{array}$ & 1089 & 1066 & 1052 & 1087,1043 & 1175,1100 \\
\hline Bending of $\mathrm{Si}-\mathrm{OH}^{67}$ & 972 & 1066 & & & \\
\hline $\begin{array}{l}\text { Symmetric bending of } \\
\mathrm{Si}-\mathrm{O}-\mathrm{Si}^{20}\end{array}$ & & & 695 & 694 & 695 \\
\hline $\begin{array}{l}\text { Asymmetric bending of } \\
\mathrm{O}-\mathrm{Si}-\mathrm{O}^{20}\end{array}$ & 474 & 539 (shoulder), 452 & 515 (shoulder), 447 & 510 (shoulder), 446 & 516 (shoulder), 470 \\
\hline
\end{tabular}




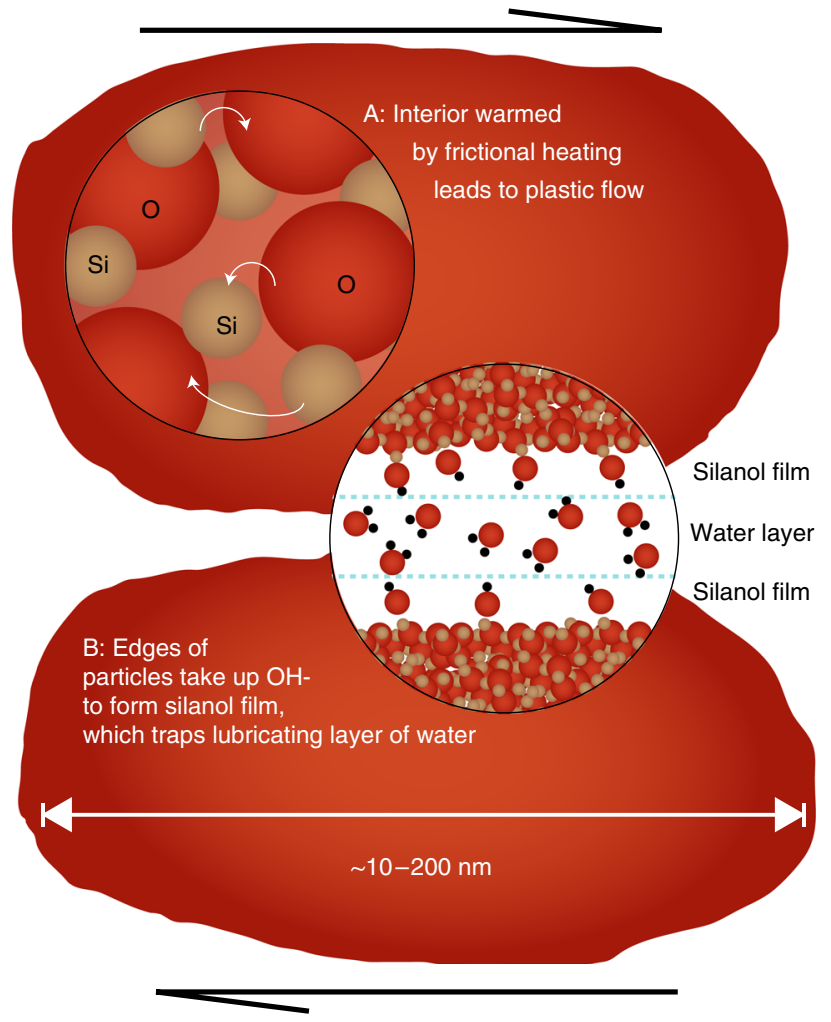

Fig. 7 Schematic cartoon showing parallel operation of two slip weakening mechanisms. See text for discussion

change the number of atoms in oligomeric rings ${ }^{39}$, and may explain the lack of any preferred coordination number in our amorphous silica wear material (Fig. 5a).

Simultaneous with intraparticle plastic deformation, hydrated particle surfaces cause a second mechanism of slip weakening (Fig. $7 \mathrm{~b} ;{ }^{40,41}$ ). Hydration is particularly effective in stressed $\mathrm{Si}-\mathrm{O}$ bonds on fresh surfaces ${ }^{42}$, forming silanol films that trap water layers of unknown thickness between the particles ${ }^{42,43}$, enabling hydrodynamic lubrication. Hydrated silica surfaces exhibit hydrophilic and hydrophobic regions, depending on silanol density $^{44}$, which create areas of interparticle repulsion and water adsorption. Hydrated surfaces on amorphous silica show a significant lubrication effect, which increases in magnitude with shearing velocity, particularly at high-stress and frictional contacts, where the increased pressure accentuates surface hydration ${ }^{40,45}$.

Post-slip healing is caused by the reversal of the same mechanisms which cause the weakening. The hydrated surfaces are particularly favorable to inter-particle bonding when the relative motion ceases. In static contact with one another, the silanol groups rearrange to construct a silica tetrahedron (siloxane), binding the particle surfaces together, and releasing a molecule of water ${ }^{46}$. The timescale of this bonding depends on contact aging, so the strength of the bond is time-dependent. This effect may explain instantaneous weakening upon re-shearing, as well as re-strengthening on $\sim 100 \mathrm{~s}$ timescales observed by Goldsby and Tullis ${ }^{5}$. We found evidence for this surface bonding in the agglomeration of particle clusters (Fig. 3c) that explode under the electron beam, showing that vaporization of the surface-bound water will disaggregate them. These are equivalent to Togo and Shimamoto's ${ }^{47}$ finding of sintering between quartz gouge grains in high velocity experiments and the formation of shiny slip surfaces in experiments similar to ours, but they did not test for the presence of amorphous silica which we observe forming these features.

Our experiments were modeled after those which first reported silica ge $^{5,6}$, but we have documented that the wear material produced in our experiments, which display the same weakening behavior, is not gel. Both the previous experiments ${ }^{5,6}$ and our experiments produced nanopowders ${ }^{48}$ and display similar weakening behaviors, but our experiments did not produce gel, perhaps due to different conditions. We therefore prefer the interpretation that the wear powder is likely responsible for the weakening behavior in both sets of experiments. Our results show that the behavior of hydrous amorphous silica nanoparticles at seismic slip rates can explain both the slip weakening and timedependent recovery in laboratory experiments. The similarity of the wear material formed at all tested slip rates shows that the mere presence of amorphous silica nanoparticles is not enough to cause the observed drastic weakening. The whole range of tested velocities $(100 \mu \mathrm{m} / \mathrm{s}-10 \mathrm{~cm} / \mathrm{s})$ are unique to earthquakes ${ }^{49}$, but the lubrication only occurred at slip velocities $>1 \mathrm{~cm} / \mathrm{s}$. Due to the strong velocity-weakening effect, the formation of this material likely promotes runaway slip. These fast slip rates are necessary to refresh interparticle contacts (preventing silica bonding) and to warm or pressurize ${ }^{24}$ the interior of the amorphous particles above the glass transition. The wear material productivity was higher in the experiments which display this weakening, suggesting that a continuous layer of $\geq 10 \mu \mathrm{m}$ thickness is required to activate silica weakening, c.f. $5,9,16$. Therefore, the formation of amorphous silica nanopowder might facilitate earthquake slip through mild weakening at small offsets or low seismic slip rates, and the extreme weakening (friction coefficient $<0.1$ ) at peak slip rate could potentially result in complete stress drop on the effected portion of earthquake rupture surfaces. As real earthquake faults are rough ${ }^{50}$, the work done in frictional heating and amorphization is not uniform across natural slip surfaces. Compared to these experiments, a natural fault might require more or faster slip in order to build up a wear material layer of sufficient thickness to cause catastrophic weakening e.g. ${ }^{51}$. Or, a continuous layer may never develop, resulting in some residual strength on the fault, and preventing complete stress drop during earthquakes, e.g., 52 . Although discrete sliding surfaces developed in patches during the experiments, they were broken and refreshed during sliding, and no through-going principal slip surface or zone was found in our samples, including those that showed extreme weakening (Fig. 3b). One possible explanation is that the polished fragments lie at a slight angle to the slip plane, as they appear to be shingled with the forward edge (upper right in Fig. $3 e$ and $f$ ) appearing to onlap the leeward edge of the neighboring fragment. It is unclear whether they formed in this orientation or were inclined due to drag of the opposite fault wall, but this pattern would prevent these slip surfaces from smoothly linking up to form a continuous shear surface across the whole sample.

Amorphous silica will crystallize to quartz within a few years at typical crustal temperatures ${ }^{53}$, with crystallization rates enhanced by the presence of hydroxyl or other impurities and by differential stress $^{54}$. Thin, translucent, nano-crystalline to micro-crystalline quartz layers have been reported on natural fault surfaces, containing patches of amorphous silica, and relict silica nanoparticles entombed in strain-free quartz crystals ${ }^{55-57}$. These continuous coatings of amorphous silica or cryptocrystalline quartz on natural fault surfaces may constitute the rock record of silica lubrication in past earthquakes.

\section{Methods}

Friction experiments. Experiments were performed using the ROtary-Shear Apparatus ROSA (built by MARUI \& CO., LTD (model MIS-233-1-77) as designed 
by T. Shimamoto). A detailed report of the design and capabilities of ROSA is provided by Rempe et al..$^{58}$. The rotation of the axial column was controlled by the $11 \mathrm{~kW}$ servomotor; the normal load was applied (on the stationary column) via a pneumatic system. Mechanical data were collected at a rate of up to $1 \mathrm{kHz}$. For the experiments reported in this paper, cylindrical novaculite samples $25 \mathrm{~mm}$ in diameter and $3.5 \mathrm{~cm}$ in length were prepared and roughened with 150 grit $\mathrm{SiC}$ paper prior to the experiment to ensure equal roughness of the sliding surfaces.

Flash heating temperature calculations. We calculated the temperature increase by flash heating in water-poor asperities: with no free water in pores around the asperities to cool them down during the experiments (following ${ }^{14}$, supplementary material).

In general, the temperature increase by frictional heating is described as:

$$
\Delta T=\frac{\tau V \sqrt{t}}{\rho c_{\mathrm{p}} \sqrt{\alpha_{\mathrm{th}} \pi}}
$$

Which at the asperity scale becomes:

$$
\Delta T_{\text {flash }}=\frac{\mu_{\mathrm{p}} P_{\mathrm{m}} V \sqrt{t_{\mathrm{c}}}}{\rho c_{\mathrm{p}} \sqrt{\alpha_{\mathrm{th}} \pi}}
$$

The properties of the wear material are poorly constrained, so we chose values conservatively to place a maximum bound on the flash heating temperature at asperities. The temperature was calculated using the properties of water-poor type I silica glass (density $\rho\left(=2200 \mathrm{kgm}^{-3}\right)$, heat capacity $c_{\mathrm{p}}\left(=1026 \mathrm{Jkg}^{-1} \mathrm{~K}^{-1}\right)$ ), and thermal diffusivity $\left.\alpha_{\mathrm{th}}=\left(6.07 \mathrm{e}-7 \mathrm{~m}^{2} \mathrm{~s}^{-1}\right){ }^{59}\right), P_{\mathrm{m}}$ is indentation strength of quartz $\left(=2.7 \mathrm{e} 9 \mathrm{~Pa},{ }^{60}\right) \mu_{\mathrm{p}}$ as our peak friction coefficient $(=0.7), V$ is our slip rate $\left(=0.0001-0.1 \mathrm{~ms}^{-1}\right)$, and $t_{\mathrm{c}}$ is contact time. Contact time is related to the radius of circular asperities $a$ and slip rate $V$ as:

$$
t_{\mathrm{c}}=\frac{a}{V}
$$

The radius of the asperities is related to the normal force $F(=1227 \mathrm{~N})$ and $P_{\mathrm{m}}$.

$$
a=\sqrt{\frac{F}{P_{\mathrm{m}} M}}
$$

Figure 2 shows the temperature increase by flash heating versus slip rate in the experiments. We used the peak friction coefficient during the experiments $(\mu=0.7)$ to calculate the heating, so actual asperity temperatures were lower once weakening began.

\section{Post-experiment sample preparation and observation. Following sliding} experiments at Padova, samples were recovered intact from the shearing apparatus, secured and sealed with tape, and sent to McGill University. Some samples were cut longitudinally (along the core axis) in order to image the sliding surface and wear material in cross section (e.g., Fig. 3a, Fig. 4). Some samples were gently opened (top novaculate core removed) to expose the sliding surface (e.g., Fig. 3b-d).

The TEM foils were prepared by J.C. White at the University of New Brunswick. The first step is preparation of a thin section which contained the entire wear layer (cross section of the intact slip surface, e.g., Fig. 3a) using CrystalBond adhesive (manufactured by SPI Supplies) to adhere the sample to the glass slide. The thin section was polished and observations were made using standard petrographic microscope and scanning electron microscope (SEM). Then, $3 \mathrm{~mm}$ copper grids were glued to the polished surface of the thin section. The thin section was immersed in acetone to gently dissolve the CrystalBond, leaving a thin $(30 \mu \mathrm{m})$ sheet of rock with copper foils on it. The copper foils help to keep the rock sheet intact especially through the slip surface area where it would be likely to break without reinforcement. Using tweezers, the thin sheet of rock is gently broken away from each copper grid, leaving only the pieces adhered to the grids. This mount is then thinned very slowly using an oblique beam at a low angle from an ion mill until the rock sheet is just perforated, and the margins of the hole are of the appropriate thickness for electron beam transparency. As the thin section was fully characterized and photographed prior to being broken up, we are able to determine exactly what is preserved and observed in the TEM foil and place that in context of the complete slip surface.

Backscattered electron images (Fig. 2, except for 2b) were collected by C. Rowe on the JEOL 8900 microprobe in the Earth and Planetary Sciences Department at McGill University. Figure 2b was collected by J.C. White using the JEOL 6400 Scanning Electron Microscope at the University of New Brunswick Microscopy and Microanalysis Facility. Transmission electron microscopy (TEM) images and diffraction patterns were collected by J.C. White using the JEOL 2011 Scanning Transmission Electron Microscope (STEM) at the Microscopy and Microanalysis Facility, University of New Brunswick. Adobe Photoshop was used to adjust brightness and contrast of the backscattered electron and transmission electron images.

Raman spectroscopy and polarizability experiments. Raman spectra were collected by K. Lamothe using the laser Raman microprobe spectrometer with $633 \mathrm{~nm}$ $\mathrm{He}-\mathrm{Ne}$ excitation laser in the Materials Chemistry lab at McGill University.

Raman spectroscopy uses a laser to interrogate a sample in order to measure the very small fraction of laser photos that are scattered inelastically, meaning the energy of the photos is shifted from interaction with the molecules in the sample. Measurement of the shift in wavelength of these photons, called the Raman shift, yields a spectrum that gives information about the vibrational modes of the molecules, which are specific to the chemical bonds and can therefore be used to gain insight into the molecular structure of the material. Raman bands are often assigned a Mulliken symbol to describe the symmetry of the modes that produced them ${ }^{61}$. The spectrum characteristic of quartz contains A1 and E bands, with A1 signifying the total symmetry and E signifying a doubly-degenerate, twodimensional irreducible representation. A concise description of normal vibrational modes is given by Tuschel ${ }^{62}$. The bands associated with amorphous silica include D bands, a name reflective of disordered structure rather than a Muliken symbol which is associated with ring modes in silica ${ }^{63,64}$.

Polarisibility experiments have shown that the wear material is highly polarization dependent (Fig. 5a). The R-band shows a strong polarization dependence for parallel $(\bar{X}(Z Z) X ; \mathrm{VV})$ versus the perpendicular $(\bar{X}(Z Y) X ; \mathrm{VH})$ polarizations (Supplementary Fig. 1) ${ }^{65}$. The $Z$-axis refers to the axis along which the incident laser beam propagates to the sample and the scattered photons return (incident electric field). The $X$-axis refers to the 'horizontal' axis for the sample, generally parallel to the front of the stage on which the sample is mounted, and $Y$ is in the plane of the stage, perpendicular to the $X$-axis. Notation for polarizability experiments is given in the form of $a(b c) d$ where $a$ is the axis along which the incident laser propagates, $b$ is the axis of polarization of the incident laser by the polarizer, $c$ is the axis of polarization of the scattered photons by the analyzer, and $d$ is the axis of propagation of the scattered photons (Supplementary Fig. 1).

\section{Data availability}

The Matlab codes used for temperature calculations including Fig. $1 \mathrm{~b}$ are archived on GitHub at https://github.com/aretu/thermalmatlabcodes. All data is available from the authors on request.

Received: 20 February 2017 Accepted: 21 December 2018 Published online: 18 January 2019

\section{References}

1. Dieterich, J. H. Modeling of rock friction: 1. experimental results and constitutive equations. J. Geophys. Res. 84, 2161-2168 (1979).

2. Di Toro, G. et al. Fault lubrication during earthquakes. Nature 471, 494-498 (2011)

3. Tullis, T. E. Mechanisms for friction of rock at earthquake slip rates, 2nd edn., Vol. 4. In Treatise on Geophysics (ed. Schubert, G.) 139-159 (Elsevier, Amsterdam, The Netherlands, 2015).

4. Lachenbruch, A. H. \& Sass, J. H. Heat flow and energetics of the San Andreas fault zone. J. Geophys. Res. 85, 6097-6112 (1980).

5. Goldsby, D. L. \& Tullis, T. E. Low frictional strength of quartz rocks at subseismic slip rates. Geophys. Res. Lett. 29, 1844-1847 (2002).

6. Di Toro, G., Goldsby, D. L. \& Tullis, T. E. Friction falls toward zero in quartz rock as slip velocity approaches seismic rates. Nature 427, 436-439 (2004).

7. Tullis, T. E. \& Goldsby, D. L. Laboratory experiments on rock friction focused on understanding earthquake mechanics: Final Technical Report for Grant Number 01-HQGR0127, Program Element III - Understanding Earthquake Processes. Tech. Rep., US Geological Survey (2003).

8. Tullis, T. E. \& Goldsby, D. L. Laboratory experiments on rock friction focused on understanding earthquake mechanics: Final Technical Report for Grant Number 02-HQGR0070, Program Element III - Understanding Earthquake Processes. Tech. Rep., US Geological Survey (2002).

9. Hayashi, N. \& Tsutsumi, A. Deformation textures and mechanical behavior of a hydrated amorphous silica formed along an experimentally produced fault in chert. Geophys. Res. Lett. 37, L12305 (2010).

10. Nakamura, Y. et al. Amorphization of quartz by friction: Implication to silicagel lubrication of fault surfaces. Geophys. Res. Lett. 39 (2012).

11. Almdal, K., Dyre, J., Hvidt, S. \& Kramer, O. Towards a phenomenological definition of the term 'gel'. Polym. Gels Netw. 1, 5-17 (1993).

12. Hirose, T. \& Shimamoto, T. Growth of molten zone as a mechanism of slip weakening of simulated faults in gabbro during frictional melting. J. Geophys. Res. 110, 18 (2005).

13. Carslaw, H. \& Jaeger, J. Heat in solids, Vol. 1 (Clarendon Press, Oxford, 1959) 
14. Violay, M. et al. Effect of water on the frictional behavior of cohesive rocks during earthquakes. Geology 42, 27-30 (2014).

15. Hoang, V. V. Molecular dynamics simulation of amorphous $\mathrm{SiO}_{2}$ nanoparticles. J. Phys. Chem. B 111, 12649-12656 (2007).

16. Reches, Z. \& Lockner, D. A. Fault weakening and earthquake instability by powder lubrication. Nature 467, 452-455 (2010).

17. Kingma, K. J. \& Hemley, R. J. Raman spectroscopic study of microcrystalline silica. Am. Mineral. 79, 269-273 (1994).

18. Anedda, A. et al. Surface hydroxyls in porous silica: a Raman spectroscopy study. Mater. Sci. Eng. C. 23, 1069-1072 (2003).

19. Aretusini, S. et al. Production of nanoparticles during experimental deformation of smectite and implications for seismic slip. Earth. Planet. Sci. Lett. 463, 221-231 (2017).

20. Hlavay, J., Jonas, K., Elek, S. \& Inczedy, J. Characterization of the particle size and the crystallinity of certain minerals by ir spectrophotometry and other instrumental methods: Ii, investigations on quartz and feldspar. Clays Clay. Miner. 26, 139-143 (1978).

21. Hemley, R. J., Jephcoat, A. P., Mao, H. K., Ming, L. C. \& Manghnani, M. H. Pressure-induced amorphization of crystalline silica. Nature 334, 52-54 (1988).

22. Kingma, K. J., Meade, C., Hemley, R. J., kwang Mao, H. \& Veblen, D. R. Microstructural observations of $\alpha$-quartz amorphization. Science 259, 666-669 (1993).

23. Dieterich, J. H. \& Kilgore, B. D. Imaging surface contacts: power law contact distributions and contact stresses in quartz, calcite, glass and acrylic plastic. Tectonophysics 256, 219-239 (1996).

24. Deb, S. K., Wilding, M., Somayazulu, M. \& McMillan, P. F. Pressure-induced amorphization and an amorphous-amorphous transition in densified porous silicon. Nature 414, 528-530 (2001).

25. Kohobhange, S. P. K., Manoratne, C. H., Pitawala, H. M. T. G. A. \& Rajapakse, R. M. G. The effect of prolonged milling time on comminution of quartz. Powder Technol. 330, 266-274 (2018).

26. Yund, R., Blanpied, M., Tullis, T. \& Weeks, J. Amorphous material in high strain experimental fault gouges. J. Geophys. Res. 95, 15589-15602 (1990).

27. Pec, M., Stu"nitz, H., Heilbronner, R., Drury, M. \& de Capitani, C. Origin of pseudotachylites in slow creep experiments. Earth. Planet. Sci. Lett. 355, 299-310 (2012).

28. Ashby, M. F. \& Verrall, R. A. Diffusion-accommodated flow and superplasticity. Acta Metall. 21, 149-163 (1973).

29. Agarwal, A. \& Tomozawa, M. Correlation of silica glass properties with the infrared spectra. J. Non-Cryst. Solids 209, 166-174 (1997).

30. Falk, M. L. \& Langer, J. S. Deformation and failure of amorphous, solidlike materials. Annu. Rev. Condens. Matter Phys. 2, 353-373 (2011)

31. Zheng, K. et al. Electron-beam-assisted superplastic shaping of nanoscale amorphous silica. Nat. Commun. 1, 24 (2010).

32. Perriot, A. et al. Raman microspectroscopic characterization of amorphous silica plastic behavior. J. Am. Ceram. Soc. 89, 596-601 (2006).

33. Yao, L., Ma, S., Platt, J. D., Niemeijer, A. R. \& Shimamoto, T. The crucial role of temperature in high-velocity weakening of faults: Experiments on gouge using host blocks with different thermal conductivities. Geology 44, 63-66 (2016).

34. Zhang, Z., Zhao, M. \& Jiang, Q. Glass transition thermodynamics of organic nanoparticles. Phys. B 293, 232-236 (2001).

35. Rharbi, Y. Reduction of the glass transition temperature of confined polystyrene nanoparticles in nanoblends. Phys. Rev. E 77, 031806 (2008).

36. De Paola, N., Holdsworth, R. E., Viti, C., Collettini, C. \& Bullock, R. Can grain size sensitive flow lubricate faults during the initial stages of earthquake propagation? Earth. Planet. Sci. Lett. 431, 48-58 (2015).

37. Green, H. II, Shi, F., Bozhilov, K., Xia, G. \& Reches, Z. Phase transformation and nanometric flow cause extreme weakening during fault slip. Nat. Geosci. 8, 484-489 (2015).

38. Gerberich, W. W. et al. Reverse plasticity in single crystal silicon nanospheres. Int. J. Plast. 21, 2391-2405 (2005).

39. Mott, N. The viscosity of vitreous silicon dioxide. Philos. Mag. B 56, 257-262 (1987).

40. Donose, B.C., Vakarelski, I.U. \& Higashitani, K. Silica surfaces lubrication by hydrated cations adsorption from electrolyte solutions. Langmuir 21, 1834-1839 (2005).

41. Sammis, C. G., Lockner, D. A. \& Reches, Z. The role of adsorbed water on the friction of a layer of submicron particles. Pure Appl. Geophys. 168, 2325-2334 (2011).

42. D'Souza \& Pantano. Mechanisms for silanol formation on amorphous silica fracture surfaces. J. Am. Ceram. Soc. 82, 1289-1293 (1999).

43. Iler, R. K. The Chemistry of Silica: Solubility, Polymerization, Colloid and Surface Properties and Biochemistry of Silica (Wiley \& Sons, New York, NY, 1979).

44. Hassanali, A. A. \& Singer, S. J. Model for the water-amorphous silica interface: The undissociated surface. J. Phys. Chem. B 111, 11181-11193 (2007).
45. Opitz, A., Ahmed, S.-U., Schaefer, J. A. \& Scherge, M. Nanofriction of silicon oxide surfaces covered with thin water films. Wear 254, 924-929 (2003).

46. Vigil, Xu, Steinberg \& Israelachvili Interactions of silicasurfaces. J. Collö̈d. Interface Sci. 165, 367-385 (1994).

47. Togo, T. \& Shimamoto, T. Energy partition for grain crushing in quartz gouge during subseismic to seismic fault motion: An experimental study. J. Struct. Geol. 38, 139-155 (2012).

48. Tullis, T. E. \& Goldsby, D. L. Laboratory experiments on rock friction focused on understanding earthquake mechanics: Final Technical Report for Grant Number 05-HQGR0087, Program Element III - Understanding Earthquake Processes. Tech. Rep., US Geological Survey (2006).

49. Rowe, C. D. \& Griffith, W. A. Do faults preserve a record of seismic slip: a second opinion. J. Struct. Geol. 78, 1-26 (2015).

50. Power, W., Tullis, T., Brown, S., Boitnott, G. \& Scholz, C. Roughness of natural fault surfaces. Geophys. Res. Lett. 14, 29-32 (1987).

51. Kirkpatrick, J. D. \& Brodsky, E. E. Slickenline orientations as a record of fault rock rheology. Earth Planet Sci. Lett. 408, 24-34 (2014).

52. Candela, T., Renard, F., Bouchon, M., Schmittbuhl, J. \& Brodsky, E. E. Stress drop during earthquakes: effect of fault roughness scaling. Bull. Seismol. Soc. Am. 101, 2369-2387 (2011).

53. Bettermann, P. \& Liebau, F. The transformation of amorphous silica to crystalline silica under hydrothermal conditions. Contrib. Mineral. Petrol. 53, 25-36 (1975).

54. Fratello, V. J., Hays, J. F. \& Turnbull, D. Dependence of growth rate of quartz in fused silica on pressure and impurity content. J. Appl. Phys. 51, 4718-4728 (1980).

55. Kirkpatrick, J. D., Rowe, C. D., White, J. C. \& Brodsky, E. E. Silica gel formation during fault slip: evidence from the rock record. Geology 41, 1015-1018 (2013).

56. Faber, C., Rowe, C. D., Miller, J. A., Fagereng, A. \& Neethling, J. H. Silica gel in fault slip surface: field evidence for palaeo-earthquakes? J. Struct. Geol. 69, 108-121 (2014).

57. Borhara, K. Assessing the Role Of Silica Gel As A Fault Weakening Mechanism In The Tuscarora Sandstone. Master's thesis, Bowling Green State University (2015).

58. Rempe, M., Smith, S. A. F., Ferri, F., Mitchell, T. M. \& Di Toro, G. Clast-cortex aggregates in experimental and natural calcite-bearing fault zones. J. Struct. Geol. 68, 142-157 (2014).

59. Bansal, N. P. \& Doremus, R. H. Handbook of Glass Properties (Academic Press, Orlando, FL, 1986).

60. Stesky, R. M. \& Hannan, S. S. Growth of contact area between rough surfaces under normal stress. Geophys. Res. Lett. 14, 550-553 (1987).

61. Cotton, F. The Crystal Field Theory. Chemical Applications of Group Theory, 3rd edn. (John Wiley \& Sons, New York, NY, 1990).

62. Tuschel, D. Practical group theory and Raman spectroscopy, part i: Normal vibrational modes. Spectroscopy 29, 14 (2014).

63. Rahmani, A., Benoit, M. \& Benoit, C. Signature of small rings in the raman spectra of normal and compressed amorphous silica: A combined classical and ab initio study. Phys. Rev. B 68, 184202 (2003).

64. Chligui, M. et al. New features in the raman spectrum of silica: Key-points in the improvement on structure knowledge. Tech. Rep., CNRS/CEMHTI (2010). https://hal.archives-ouvertes.fr/hal-00520823/document.

65. Hehlen, B. \& Simon, G. The vibrations of vitreous silica observed in hyperraman scattering. J. Raman Spectr. 43, 1941-1950 (2012).

66. Hair, M. L. Hydroxyl groups on silica surface. J. Non-Cryst. Solids 19, 299-309 (1975).

67. Meng, Z. et al. Preparation of highly monodisperse hybrid silica nanospheres using a one-step emulsion reaction in aqueous solution. Langmuir 25, 7879-7883 (2009)

68. Ying, J. Y., Benziger, J. B. \& Navrotsky, A. Structural evolution of alkoxide silica gels to glass: effect of catalyst pH. J. Am. Ceram. Soc. 76, 2571-2582 (1993).

\section{Acknowledgements}

This work was supported by NSERC Discovery Grants to C.D.R. and J.C.W., the Wares Faculty Scholarship to C.D.R., and by the ERC CoG 614705 NOFEAR Grant to G.D.T. and M.R.

\section{Author contributions}

C.D.R. conceived the study, performed microprobe and XRD analyses, and prepared the manuscript and figures. K.L. and M.A. performed Raman and FTIR experiments, interpreted the data, and contributed text and figures to the manuscript. M.R. and T.M. performed the shearing experiments with supervision and support from G.D.T., who contributed to interpretation of all results and performed temperature calculations. J.C.W. made SEM and TEM observations of the wear material and contributed figures. S.A. contributed three temperature models, supplementary figures, and text. 


\section{Additional information}

Supplementary Information accompanies this paper at https://doi.org/10.1038/s41467018-08238-y.

Competing interests: The authors declare no competing interests.

Reprints and permission information is available online at http://npg.nature.com/ reprintsandpermissions/

Journal peer review information: Nature Communications thanks the anonymous reviewers for their contribution to the peer review of this work. Peer reviewer reports are available.

Publisher's note: Springer Nature remains neutral with regard to jurisdictional claims in published maps and institutional affiliations. (c) (i) Open Access This article is licensed under a Creative Commons Attribution 4.0 International License, which permits use, sharing, adaptation, distribution and reproduction in any medium or format, as long as you give appropriate credit to the original author(s) and the source, provide a link to the Creative Commons license, and indicate if changes were made. The images or other third party material in this article are included in the article's Creative Commons license, unless indicated otherwise in a credit line to the material. If material is not included in the article's Creative Commons license and your intended use is not permitted by statutory regulation or exceeds the permitted use, you will need to obtain permission directly from the copyright holder. To view a copy of this license, visit http://creativecommons.org/ licenses/by/4.0/.

(C) The Author(s) 2019 